\title{
KEANEKARAGAMAN JENIS JAMUR MAKROSKOPIS DI BUKIT WANGKANG DESA SUNGAI AMBAWANG KABUPATEN KUBU RAYA
}

\author{
(Macroscopic Mushroom Diversity In The Wangkang Hill The Ambawang River Village \\ Districts Of Kubu Raya)
}

\author{
Melinda Zulpitasari, Wiwik Ekyastuty, H.A. Oramahi \\ Fakultas Kehutanan Universitas Tanjungpura Jl. Daya Nasional, Pontianak 78124 \\ Email: melindazulpitasari12@gmail.com
}

\begin{abstract}
Macroscopic fungi important role for ecosystem sustainable forest. Research to diversity of species macroscopic fungi in area Bukit Wangkang, Sungai Ambawang village. The research was counducted by survey method with multiple plot techniques. Laying of plots by means of purposive sampling, plots measuring $5 \mathrm{~m} \times 5 \mathrm{~m}$. obtained 23 plot observations total area of 0,0575 $\mathrm{Ha}$, total research area of $3700 \mathrm{Ha}$. The research area, found 29 macroscopic fungi from 13 families, the families polyporaceae many of 10 species, then hymenochaetaceae many of 4 (four) types and ganodermataceae many of 3 (three) types. The high INP value Mycena sp (26,571), Xylaria sp 1 $(23,3312)$ and Xylaria sp $2(13,8331)$. Discovered 8 (eight) species macroscopic fungi can be consumed such as ganoderma lucidum as medicinal ingredient which processed of powder and Lentinus tigrinus as food ingredients boiled or sautéed. Macroscopic fungi cannot be consumed like rigidoporus microporus because it has fruiting body that is hard, and poisonous fungi species such as coltricia sp and microporus sp types used as souvenir. 29 species of fungi founded 4 (four) species fungi grow out of the ground and 25 species types other in dead wood. Obtained 23 plots with three types of canopy density where density rarely obtained 6 (six) species of macroscopis fungi of 4 (four) plot, then density obtained 10 of fungi of 9 (nine) plot observation. Density obrained 13 fungi of 10 plot observations.
\end{abstract}

Keywords: Edible mushroom, Macroscopic fungi, Secondary forest

\section{PENDAHULUAN}

Indonesia merupakan negara kaya akan sumber daya alam, memiliki potensi keanekaragaman hayati yang tinggi di dalamnya. Keanekaragaman hayati adalah keseluruhan variasi berupa bentuk, penampilan, jumlah dan sifat yang dapat ditemukan pada mahluk hidup. Keanekaragaman hayati Indonesia mampu memberikan manfaat berupa manfaat ekonomi, sosial budaya, wisata dan ilmu pengetahuan. Indonesia memiliki banyak jenis hewan (fauna) dan tumbuhan (flora) yang dapat diperbarui dan dimanfaatkan secara berkelanjutan. Salah satu diantara kekayaan hayati tersebut adalah jenisjenis jamur makroskopis.

Habitat jamur di hutan pada umumnya ada di semua kayu dan serasah daun membusuk yang menyediakan berbagai bahan organik mati yang menjadi makanan jamur. Sebagian besar jamur dapat ditemukan hidup pada tanah-tanah yang mengandung serasah, dahan-dahan pohon besar yang telah 
lapuk dan sebagian terdapat pada pohon yang masih hidup (misalnya jamur Auricularia spp.) atau rumput-rumputan yang terdapat pada beberapa wilayah di bukit selama musim penghujan saja (Proborini, 2012). Jamur memiliki fungsi yang beranekaragam, beberapa jenis jamur telah banyak dimanfaatkan oleh manusia sebagai bahan makanan dan sumber bahan obat-obatan tradisional maupun modern. Di beberapa belahan dunia, pemanfaatan jamur telah menjadi semakin meluas sejalan dengan semakin genjarnya penelitian mengenai peran jamur dalam dunia kesehatan (bahan fitofarmaka), dan jamur liar juga memberikan kontribusi ekonomi yang cukup nyata pada masyarakat sekitar hutan (Wahyudi, 2012). Namun ada juga jenis-jenis tertentu yang mengandung racun sangat bebahaya dan kalau dikonsumsi bisa menyebabkan kematian (Murniarti, 2010).

Bukit Wangkang merupakan suatu kawasan hutan konservasi yang termasuk ke dalam kategori hutan dataran rendah dengan ketinggian \pm 300 m dpl. Kawasan Bukit Wangkang yang dekat dengan kawasan pemukiman masyarakat tidak terlepas dari campur tangan manusia, dan banyak hasil hutannya yang dimanfaatkan oleh masyrakat setempat. Salah satu hasil hutan yang dimanfaatkan oleh masyarakat setempat adalah jamur sebagai bahan makanan dan juga obatobatan tradisional. Di sisi lain potensi dan keanekaragaman jenisnya belum diketahui. Sehingga penelitian ini perlu dilakukan guna mendata dan mengetahui jenis-jenis beserta manfaat jamur makroskopis yang berada di atas permukaan tanah kawasan Bukit Wangkang.

\section{METODE PENELITIAN}

Penelitian dilaksanakan di kawasan hutan lindung Bukit Wangkang Desa Sungai Ambawang Kabupaten Kubu Raya. Penelitian ini menggunakan metode survei dengan teknik petak ganda. Peletakan petak di lapangan dengan cara purposive sampling, menggunakan petak berukuran $5 \mathrm{~m}$ x $5 \mathrm{~m}$. Dasar dari peletaan petak dengan purposive sampling adalah ditemukannya populasi jamur makroskopis yang berada di lantai hutan, dan pembuatan petak berdasarkan kondisi kerapatan tajuk yang terdapat di lapangan, yang distratifikasi menjadi tiga yaitu rapat, cukup dan jarang. Menurut Kadri (1992) kerapatan tajuk dibedakan menjadi tiga kelas yaitu kerapatan tajuk rapat penutupan tajuknya $>70 \%$, kerapatan tajuk cukup penutupan tajuknya 40-70\%, dan kerapatan tajuk jarang penutupan tajuknya $<40 \%$. Penentuan kondisi kerapatan tajuk dengan menggunakan alat densiometer. Di setiap stratifikasi dibuat enam petak pengamatan dengan ukuran $5 \mathrm{~m} \times 5 \mathrm{~m}$, sehingga diperoleh 23 petak pengamatan dengan luas total area pengmatan 0,0575 ha.

Pengambilan data meliputi tempat tumbuh jamur yaitu kayu mati atau serasah. Jumlah jenis yang ditemukan dicatat dan karakteristik jamur seperti warna, bentuk dan ukuran tubuh jamur yang ditemui untuk mengidentifikasi 
jenis jamur tersebut. Indentifikasi jamur menggunakan buku Mushrooms Of North America (Phillips, 1999), Mushrooms (Laessoe, 2002), Mushrooms and Toadstools (Else, 1970) dan Mushrooms TNGR (Teguh, Wasmat, Isnan, Suparmo, 2011) dan jurnal hasil penelitian Annisa (2017), Priskila (2018).

\section{HASIL DAN PEMBAHASAN}

Identifikasi jenis dan jumlah jamur makroskopis di kawasan penelitian ditemukan 29 jenis jamur makroskopis dari 13 famili, famili terbanyak adalah Polyporaceae sebanyak 10 jenis, diikuti Hymenochaetaceae sebanyak 4 jenis kemudain Ganodermataceae sebanyak 3 jenis. Dari 29 jenis diperoleh dua divisi yaitu Basidiomycota sebanyak 25 jenis dan Ascomycota sebanyak 4 jenis. Jamur makroskopis yang ditemukan di areal pengamatan didominasi oleh divisi Basidiomycota. Spesies jamur makroskopis yang termasuk dalam divisi Ascomycota yaitu jenis Cookeina sulcipes, Cookeina tricholoma, Xylaria hypoxylon, dan Xylaria polymorpha yang terbagi dari 2 ordo dan dan 2 famili. Jamur makroskopis dari divisi Basidiomycota tergolong dalam 8 ordo dan 9 famili.

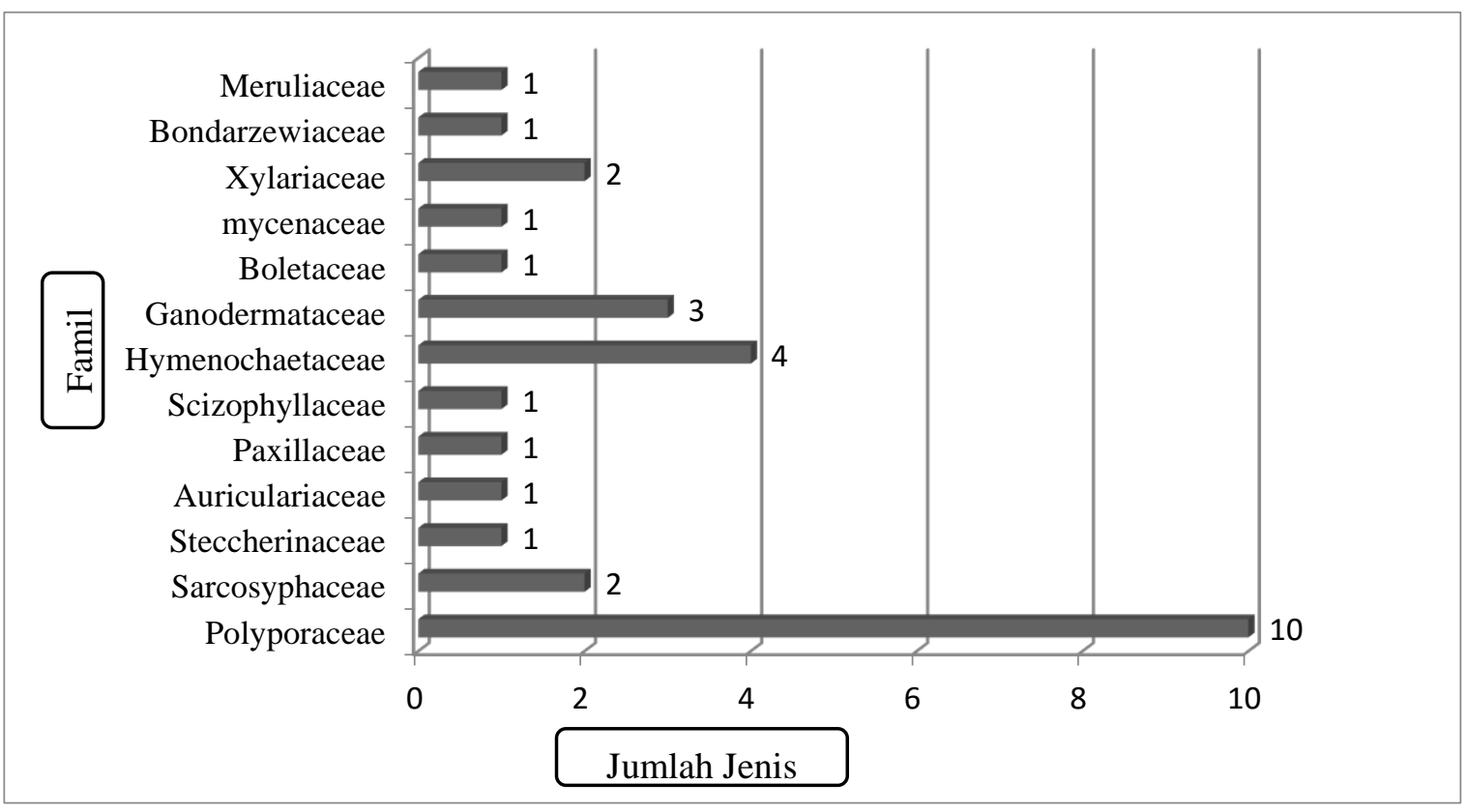

Gambar 1. Jumlah jenis dan famili jamur makroskopis (The number and type of macroscopic fungi families)

Hal ini berbeda dengan hasil penelitian Priskila (2018) di kawasan hutan sekunder areal IUPHHK-HTI PT. Bhatara Alam Lestari desa Bukit Batu Kabupaten Mempawah dari jumlah jenis ditemukan 33 spesies jamur makroskopis yang termasuk dalam 15 famili. Jenis jamur yang sama ditemukan hanya $18 \%$, sangat sedikit kesamaan jenis yang ditemukan dari hasil penelitian yang ditemukan di kawasan hutan lindung Bukit Wangkang Desa 
Sungai Ambawang Kabupaten Kubu Raya. Jumlah jenis sedikit bisa saja disebabkan oleh peristiwa alam seperti kebakaran hutan, kawasan hutan lindung yang dijadikan masyarakat sebagai tempat objek wisata juga masih aktifnya kegiatan perburuan yang dilakukan oleh masyarakat setempat dan perubahan iklim yang sangat menentukan pertumbuhan jamur pada umumnya.

Hasil penelitian menunjukan bahwa spesies jamur makroskopis yang ditemukan umumnya didominasi oleh family Polyporaceae. Family Polyporaceae merupakan family terbanyak dengan 10 jenis jamur makroskopis. Menurut Tampubolon (2012), polyporaceae merupakan satu diantara beberapa family terbesar yang memiliki banyak warna, bentuk dan ukuran. Tampubolon (2012) juga menyatakan bahwa family polyporaceae memiliki ciri umum berbentuk braket atau kipas dengan permukaan hymenium berupa lubang-lubang kecil yang disebut pores atau modifikasinya. Tubuh buahnya berkayu, tebal dan kasar, kebanyakan tumbuh pada kayu.

Kondisi tempat tumbuh jamur makroskopis dari hasil pengukuran yang dilakukan seperti rata-rata suhu udara $(29,09)$, rata-rata kelebaban udara $(88,27)$ serta kerapatan tajuk. Menurut Suarnadwipa dan Hendra (2008) jamur dapat tumbuh pada tanah yang lembab, memiliki kerapatan tajuk yang rapat serta memiliki suhu udara yang rendah, sehingga jamur dapat tumbuh dengan baik. Hasil dari pengamatan kerapatan tajuk diperoleh 4 petak pengamatan yang kerapatan tajuknya jarang, diikuti 9 petak pengamatan kerapatan tajuknya sedang kemudian 10 petak pengamatan dengan kerapatan tajuknya rapat. Kondisi ini menunjukan bahwa jamur makroskopis mampu beradaptasi dengan lingkungannya. Jamur makroskopis banyak ditemukan pada tutupan tajuk rapat dan sedang di bandingkan tutupan tajuk jarang, sesuai dengan pernytaan Putir et al, (2008) yang menyatakan bahwa ketersediaan air pada substrat dan kelembaban udara menjadi tempat yang cocok untuk pertumbuhan jamur makroskopis.

Diperoleh 4 petak pengamatan dari hasil penelitian yang memiliki kerapatan tajuk jarang dengan 6 jenis jamur makroskopis dari 4 famili. Diperolehnya kerapatan tajuk jarak karena kondisi kawasan yang terbakar sehingga kurangnya ditemukan jamur makroskopis. Jenis-jenis jamur yang ditemukan di kerapatan tajuk jarang juga merupakan jenis jamur yang memiliki tubuh buah keras. Secara lengkap dapat dilihat pada Tabel 1. 
Tabel 1. Keanekaragaman jenis jamur makroskopis berdasarkan tipe kerapatan tajuk (Diversity of macroskopic fungi by type of crown density)

\begin{tabular}{lllll}
\hline No & Petak & Jenis & $\begin{array}{l}\text { Jumlah } \\
\text { Individu }\end{array}$ & $\begin{array}{l}\text { Kerapatan Tajuk } \\
<40 \%\end{array}$ \\
\hline 1 & 8 & Inonotus sp & 5 & 33 \\
2 & 9 & Tapinella sp 2 & 12 & 13 \\
& & Schizophyllum sp & 9 & \\
3 & 10 & Phellinus sp 1 & 3 & 34 \\
4 & 11 & Ganoderma sp 1 & 6 & 22 \\
\hline Jumlah & & 11 & \\
\hline
\end{tabular}

Faktor lebih banyaknya ditemukan jamur pada kerapatan tajuk sedang dan rapat dikarenakan suhu udara yang rendah serta masih rimbunnya pepohonan membuat pertumbuhan jamur lebih mudah berkembang, selain itu juga kelembaban udara yang tinggi karena dikelilingi oleh sungai. Dari hasil penelitian diperoleh 10 jenis jamur maksroskopis dari 5 famili yang berada di kerapatan tajuk sedang. Terdapat 9 petak pengamatan dengan jumlah individu sebanyak 135 , sedangkan pada kerapatan tajuk rapat diperoleh 13 jenis jamur makroskopis dari 7 famili dengan jumlah petak pengamatan sebanyak 10 petak. Berbeda dengan hasil penelitian Juliati (2018) di Hutran Rawa Gambut Sekunder Desa Kuala Dua Kabupaten Kubu Raya hasil yang diperoleh 17 jenis jamur pada kerapatan tajuk rapat dan 7 jenis jamur masing-masing pada kerapatan tajuk sedang dan jarang, hal ini disebabkan karena hutan rawa gambut memiliki tingkat kelembaban yang lebih tinggi sehingga mendukung pertumbuhan jamur dengan baik. Secara lengkap dapat dilihat pada Tabel 2 dan Tabel 3.

Tabel 2. Keanekaragaman jenis jamur makroskopis berdasarkan tipe kerapatan tajuk (Diversity of macroskopic fungi by type of crown density)

\begin{tabular}{lllll}
\hline \multirow{2}{*}{ No } & \multirow{2}{*}{ Petak } & \multirow{2}{*}{ Jenis } & $\begin{array}{l}\text { Jumlah } \\
\text { Inidividu }\end{array}$ & $\begin{array}{l}\text { Kerapatan Tajuk } \\
40-70 \%\end{array}$ \\
\hline 1 & 4 & Cookeina sp 2 & 1 & 60 \\
2 & 5 & Irpex sp & 9 & 50 \\
3 & 7 & Polyporus sp 2 & 33 & 57 \\
4 & 15 & Xylaria sp 2 & 42 & 64 \\
5 & 17 & Heterobasidion sp & 1 & 68 \\
6 & 18 & Pycnoporus sp & 7 & 69 \\
7 & 20 & Lentinus sp 2 & 33 & 64 \\
8 & 22 & Climacodon sp & 1 & 64 \\
9 & 23 & Lentinus sp 3 & 7 & 69 \\
\hline Jumlah & Rigidoporus sp & 1 & \\
\hline
\end{tabular}


Tabel 3. Keanekaragaman jenis jamur makroskopis berdasarkan tipe kerapatan tajuk (Diversity of macroskopic fungi by type of crown density)

\begin{tabular}{lllll}
\hline \multirow{2}{*}{ No } & \multirow{2}{*}{ Petak } & Jenis & $\begin{array}{l}\text { Jumlah } \\
\text { Inidividu }\end{array}$ & $\begin{array}{l}\text { Kerapatan Tajuk } \\
>70 \%\end{array}$ \\
\hline 1 & 1 & Tremetes sp & 15 & 79 \\
2 & 2 & Cookeina sp 1 & 2 & 84 \\
3 & 3 & Polyporus sp. 1 & 5 & 84 \\
4 & 6 & Auricularia sp & 4 & 92 \\
5 & 12 & Ganoderma sp 2 & 3 & 92 \\
6 & 12 & Tyopilus sp. & 1 & 92 \\
7 & 12 & Mycena sp & 112 & 92 \\
8 & 12 & Amauroderma sp & 5 & 92 \\
9 & 13 & Phellinus sp 2 & 1 & 71 \\
10 & 14 & Xylaria sp 1 & 97 & 90 \\
11 & 16 & Microporus sp & 29 & 73 \\
12 & 19 & Coltricia sp & 6 & 90 \\
13 & 21 & Lentinus sp 2 & 2 & 74 \\
\hline \multicolumn{5}{l}{ Jumlah }
\end{tabular}

Hasil penelitian yang telah dilakukan dari 29 jenis jamur makroskopis ditemukan 3 jenis tumbuh di serasah atau diatas tanah dan 26 jenis tumbuh di atas kayu mati. Berdasarkan persentase jenis jamur makroskopis yang tumbuh di serasah $(13,80 \%)$, dan jenis yang tumbuh pada kayu mati $(86,20 \%)$. Jenis jamur makroskopis yang ditemukan secara keseluruhan hidup pada kayu mati, tempat tumbuh lainnya adalah serasah Menurut Jumiarti (2011) dapat diketahui bahwa kayu mati menjadi tempat tumbuh jamur yang dominan dikarenakan kayu yang sudah mati terdapat substrat yang mengandung sumber makanan bagi jamur (Tabel 4).

Tabel 4. Data tempat tumbuh Jamur pada area penelitian (Fungi growing data in the study area)

\begin{tabular}{llll}
\hline No & Tempat Tumbuh & Individu & Persentase (\%) \\
\hline 1 & Serasah & 45 & 9,82 \\
2 & Kayu Mati & 413 & 10,18 \\
\hline Jumlah & & 458 & $100 \%$ \\
\hline
\end{tabular}

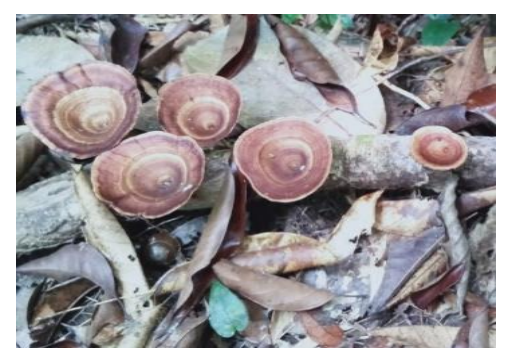

(a)

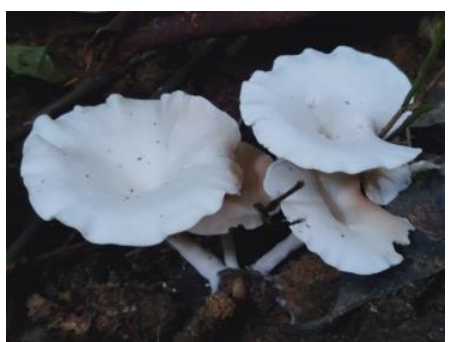

(b) 
Gambar 2. (a) Jamur Microporus sp ditemukan tumbuh pada kayu mati dan Lentenus sp.1 (b) ditemukan tumbuh pada serasah (a. Mushroom Microporus sp. found growing on dead wood and b. mushroom Lentenus sp. 1 found in litter)

Suhu dan kelembaban merupakan faktor penting penunjang pertumbuhan jamur, suhu yang rendah dan kelembaban yang tinggi biasanya dikarenakan kerapatan tajuk suatu kawasan yang sangat rapat juga karena kawasan yang dikelilingi sungai. Annissa (2017) juga mengatakan bahwa faktor abiotik yang mempengaruhi penyebaran dan pertumbuhan jamur diantaranya adalah iklim, suhu udara, cahaya dan kelebaban udara, sehingga kondisi menjadi salah satu faktor yang menentukan rendah atau tingginya keanekaragamn jenis jamur dalam kawasan penelitian.

Jenis jamur yang ditemukan di kawasan penelitian termasuk dalam jenis jamur mesofilik. Jamur mesofilik tumbuh pada kisaran suhu $25^{\circ} \mathrm{C}-37^{\circ} \mathrm{C}$. kondisi suhu sangat berhubungan dengan kelembaban, bila suhu semakin tinggi akan menyebabkan penguapan semakin besar sehingga kelembban menurun. Hasil pengukuran kelembaban rata-rata $88,27 \%$. Hal ini sesuai dengan pendapat Gandjar et al,(2006), bahwa jamur dapat tumbuh pada kisaran kelebaban udara 70\%-90\%. Hasil pengukuran yang dilakukan di Bukit Wangkang tidak jauh berbeda dengan penelitian yang di lakukan oleh Annissa (2017) di Arboretum Sylva Universitas Tanjungpura dengan hasil pengukuran suhu rata-rata $29,04^{\circ} \mathrm{C}$ dan kelebaban rata-rata $84,66 \%$.

Hasil analisis yang dilakukan di areal penelitian telah doperoleh nilai kepadatan individu jamur makroskopis tertinggi adalah jenis Mycena sp dengan tingkat kepadatan 112 individu/ha dengan kepadatan relatifnya $24,19 \%$, diikuti oleh jenis Xylaria sp 1 dengan tingkat kepadatan 97 individu/ha dan kepadatan relatifnya $20,95 \%$, dan jenis Xylaria sp 2 tingkat kepadatan 42 individu/ha dengan kerapatan relatifnya 9,07\%. Kepadatan jamur makroskopis dengan jumlah individu yang tergolong sangat sedikit, hal ini bisa saja dipengaruhi oleh kondisi tempat tumbuh jamur makroskopis seperti suhu dan kelembaban udara disekitar tempat tumbuh jamur. Tampubolon (2012), menyatakan bahwa suhu dan kelembaban udara secara ekologis merupakan faktor lingkungan yang paling penting.

Hasil analisis indeks dominansi $(\mathrm{C}<1=0,0050)$ menunjukan bahwa komunitas jamur makroskopis pada kawasan penelitian tidak hanya didominasi satu jenis saja melainkan ada beberapa jenis yang mendominasi (Tabel 9). Hal ini menunjukan tidak terjadinya pemusatan terhadap jenis jamur makroskopis tertentu yang ditemukan dikawasan penelitian. 

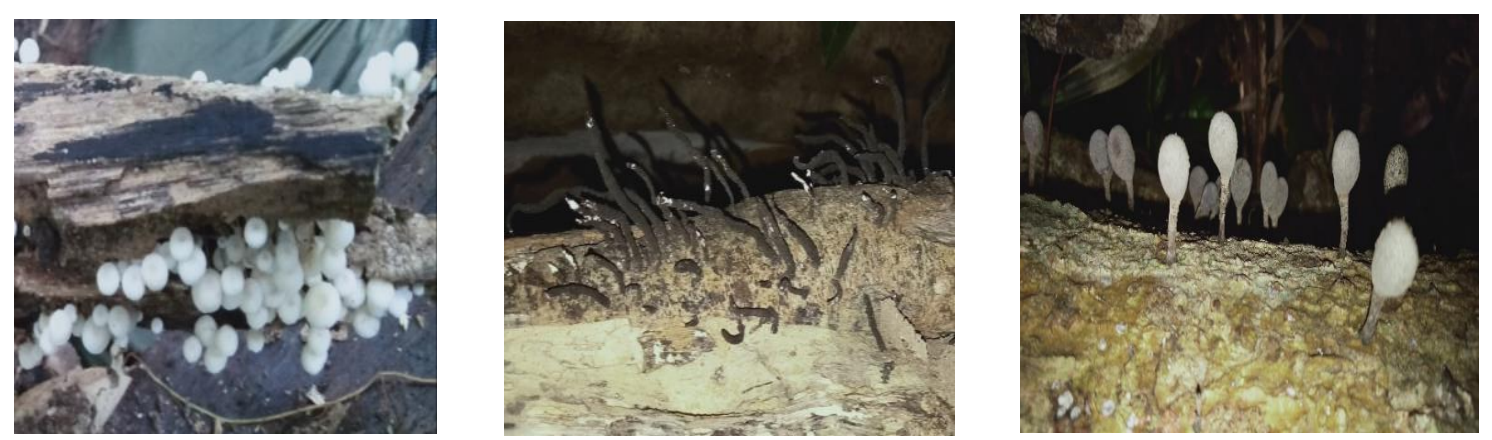

Gambar 3. Jamur Yang Memiliki Nilai Kepadatan Individu Tertinggi (a). Mycena sp. (b). Xylaria sp. 1 (c). Xylaria sp. 2 (Mushroom that have the highest individual density values (a). Mycena sp. (b). Xylaria sp. 1 (c). Xylaria sp. 2)

Tabel 5. Rekapitulasi Indeks Nilai Penting (INP)dan Indeks Dominansi (C) Jenis Jamur Makroskopis (Recapitulation Of Importrant Value Index (INP) and Dominance Index (C) Of Macroscopic Fungi)

\begin{tabular}{|c|c|c|c|c|}
\hline No & Nama Jenis & $\begin{array}{l}\text { Jumlah } \\
\text { Individu }\end{array}$ & INP & $\mathrm{C}$ \\
\hline 1 & Tremetes $\mathrm{sp}$ & 15 & 10,3825 & 0,0003 \\
\hline 2 & Polyporus sp. 1 & 5 & 3,4608 & 0,0001 \\
\hline 3 & Polyporus sp 2 & 33 & 9,5083 & 0,0002 \\
\hline 4 & Polyporus sp 3 & 11 & 4,7567 & 0,0001 \\
\hline 5 & Microporus sp & 29 & 15,7873 & 0,0004 \\
\hline 6 & Pycnoporus sp & 7 & 6,2737 & 0,0002 \\
\hline 7 & Lentinus sp 1 & 33 & 9,5083 & 0,0002 \\
\hline 8 & Lentinus sp 2 & 2 & 2,8129 & 0,0001 \\
\hline 9 & Lentinus sp 3 & 7 & 3,8928 & 0,0001 \\
\hline 10 & Rigidoporus sp & 1 & 2,5969 & 0,0001 \\
\hline 11 & Cookeina sp 1 & 2 & 5,1938 & 0,0001 \\
\hline 12 & Cookeina sp 2 & 1 & 2,5969 & 0,0001 \\
\hline 13 & Irpex $\mathrm{sp}$ & 9 & 4,3247 & 0,0001 \\
\hline 14 & Auricularia sp & 4 & 3,2448 & 0,0001 \\
\hline 15 & Tapinella $\mathrm{sp}$ & 12 & 7,3536 & 0,0002 \\
\hline 16 & Schizophyllum sp & 9 & 4,3247 & 0,0001 \\
\hline 17 & Phellinus sp 1 & 3 & 7,7908 & 0,0002 \\
\hline 18 & Coltricia sp & 6 & 3,6768 & 0,0001 \\
\hline 19 & Phellinus sp & 1 & 2,5969 & 0,0001 \\
\hline 20 & Inonotus sp & 5 & 3,4608 & 0,0001 \\
\hline 21 & Ganoderma sp 1 & 6 & 6,0578 & 0,0002 \\
\hline 22 & Ganoderma sp 2 & 3 & 3,0289 & 0,0001 \\
\hline 23 & Amauroderma sp & 5 & 5,8418 & 0,0001 \\
\hline 24 & Tyopilus sp. & 1 & 2,5969 & 0,0001 \\
\hline 25 & Mycena sp & 112 & 26,571 & 0,0007 \\
\hline 26 & Xylaria sp 1 & 97 & 23,3312 & 0,0006 \\
\hline 27 & Xylaria sp 2 & 42 & 13,8331 & 0,0003 \\
\hline 28 & Heterobasidion $\mathrm{sp}$ & 1 & 2,5969 & 0,0001 \\
\hline 29 & Climacodon sp & 1 & 2,5969 & 0,0001 \\
\hline \multicolumn{2}{|c|}{ Jumlah } & 548 & 200 & 0,0050 \\
\hline
\end{tabular}


Tabel 6. Rekapitulasi Indeks Keanekaragaman Jenis (H'), Indeks Kelimpahan Jenis (e), dan Indeks Kekayaan Jenis (d) Jamur Makroskopis (Recapitulation Of Species Diversity Index (H'), Species Abudance Index (e) and Species Wealth Index (d) Macroscopic Fungi)

\begin{tabular}{lll}
\hline No & Analisis & Total \\
\hline 1 & Indeks Keanekaragaman Jenis (H') & 1,0308 \\
2 & Indeks Kelimpahan Jenis (e ) & 0,1079 \\
3 & Indeks Kekayaan Jenis (d) & 10,5229 \\
\hline
\end{tabular}

$\begin{array}{lrr}\text { Hasil perhitungan } & \text { indeks } \\ \text { keanekaragaman } & \text { jenis } & \text { jamur } \\ \text { makroskopis di kawasan } & \text { penelitian } \\ \text { menunjukan nilai keanekaragaman jenis } \\ \text { sedang karena memiliki nilai } 1,0308 \text {. }\end{array}$ Berbeda dengan hasil penelitian Annissa (2017) di Arboretum Sylva Universitas Tanjungpura yang memiliki nilai indeks keanekaragaman jenis dengan kategori tinggi $\left(\mathrm{H}^{\prime}=3,0385\right)$. Hal ini disebabkan oleh musim kemarau hingga tidak terjadi hujan sebelum bahkan selama penelitian, faktor lainnya adalah lokasi penelitian yang dijadikan sebagai kawasan wisata bukit wangkang serta masih aktifnya kegiatan berburu oleh masyarakat (Tabel $6)$.

Indeks kelimpahan jenis untuk mengetahui kelimpahan (kemerataan) jenis-jenis jamur dalam areal pengamatan. Hasil perhitungan nilai indeks kelimpahan jenis adalah 0,1079 yang diartikan bahwa kelimpahan jenis jamur makroskopis di kawasan hutan lindung Bukit Wangkang Desa Sungai Ambawang Kabupaten Kubu Raya tergolong merata (Tabel 6).

Hasil perhitungan dari penelitian yang dilakukan menunjukan bahwa kekayaan jenis jamur makroskopis termasuk sedang $(10,5229)$ (Tabel 10). Hal ini disebabkan indeks kekayaan jenis berbanding lurus dengan nilai keanekaragaman jenis yang sangat ditentukan oleh jumlah jenis jamur makroskopis yang ditemukan. Berbeda dengan hasil penelitian Priskila (2018) di Kawasan Hutan Sekunder Areal IUPHHK-HTI PT. Bhatara Alam Lestari Kabupaten Mempawah memiliki nilai indeks kekayaan jenis 13,2143 dengan jumlah jamur yang ditemukan sebanyak 33 jenis.

Hasil penelitian di lapangan untuk pemanfaatan jamur makroskopis ditemukan 6 jensi jamur yang dapat dikonsumsi sebagai bahan makanan dan 3 jenis jamur makroskopis sebagai bahan obat-obatan. Terdapat 1 jenis jamur yang biasa digunakan sebagai souvenir yaitu jenis Microporus sp karena tubuh buah yang menyerupai bunga dengan warna coklat tua dan muda yang mengkombinasi kemudain struktur tubuh buah yang keras, dan jenis lainnya tidak dapat dikonsumsi seperti Coltricia sp jenis jamur yang beracun.

Hasil penelitian ditemukan 8 jenis jamur makroskopis yang dapat dikonsumsi seperti Ganoderma sp 1 sebagai bahan obat-obatan yang diolah berupa bubuk, dan Lentinus sp 1 sebagai bahan makanan dengan cara direbus atau ditumis. Jamur makroskopis yang tidak 
dapat dikonsusmsi seperti Rigidoporus sp karena memiliki tubuh buah yang liat dan keras, dan jenis jamur beracun seperti Coltricia sp dan juga jenis Microporus sp yang bisa dijadikan sebagai souvenir. Terdapat 25 jenis jamur saprofit yang hidupnya menumpang pada batang kayu yang sudah mati yang dapat membantu peleburan batang kayu tersebut, sedangkan 4 jenis jamur lainnya ektomikoriza atau tumbuh diatas permukaan tanah dan memiliki akar juga menyerap unsur hara yang ada di atas tanah.

\section{Kesimpulan}

Di temukan 29 jenis jamur makroskopis kawasan hutan lindung Bukit Wangkang Desa Sungai Ambawang Kabupaten Kubu Raya dari 13 famili, dan famili terbanyak adalah Polyporaceae dengan 10 spesies. Semua jenis jamur yang ditemukan termasuk dalam decomposer, 4 spesies yang tumbuh di serasah dan 25 spesies tumbuh di kayu mati. Pemanfaatan jamur makroskopis ditemukan 8 jenis yang dapat dikonsumsi baik sebagai bahan makanan maupun sebagai bahan obatobatan, dan 21 jenis laiinnya tidak dapat dikonsumsi.

\section{Saran}

Perlu adanya penelitian lanjutan tentang pengelolaan dan pemanfaatan jamur makroskopis yang ditemukan di kawasan hutan lindung Bukit Wangkang Desa Sungai Ambawang Kabupaten Kubu Raya. Kondisi hutan lindung Bukit Wangkang Desa Sungai Ambawang Kabupaten Kubu Raya yang cukup baik dan menjadi tempat tumbuh jamur makroskopis yang memadai, sehingga perlu dipertahankan keberadaan dan kelestariannya terutama jamur yang memiliki manfaat sebagai obat dan bahan masakan.

\section{DAFTAR PUSTAKA}

Annissa I. 2017. Keanekaragaman jenis jamur makroskopis di arboretum sylva universitas tanjungpura. Fakultas Kehutanan, Universitas Tanjungpura, Pontianak. Jurnal Hutan Lestari 5(4): 969-977

Else, Hvass H. 1970. Mushrooms And Toadstools. London: High Holborn.

Gandjar I, Wellyzar S, Ariyanti O. 2006. Mikologi Dasar dan Terapan. Jakarta: Yayasan Obor Indonesia.

Juminarti L. 2011. Keanekaragaman jenis jamur kayu maksroskopis dalam kawasan hutan adat pengajit desa sahan kecamatan seluas Kabupaten Bengkayang. Fakultas Kehutanan, Universitas Tanjungpura, Pontianak. Jurnal Hutan Lestari 1(1): 8-11.

Leassoe T, Lincoff G. 2002. Mushrooms. London: Dorling Kindersley Limited.

Muniarti N. 2010. Keanekaragaman jenis jamur kayu makroskopis di hutan rawa gambut pada plot permanen simpur hutan desa kuala dua Kabupaten Kubu Raya, Iniversitas Tanjungpura, Fakultas Kehutanan, Pontianak. Jurnal Hutan Lestari 1(1): 171-176.

Phillips R. 1999. Mushrooms Of North America. Canada: Little, Brown and Company. 
Priskila. 2018. Keanekaragaman Jenis jamur makroskopis di kawasan hutan sekunder areal iphhk-hti pt. bhantara alam lestari Kabupaten Mempawah. Fakultas Kehutanan, Universitas Tanjungpura, Pontianak. Jurnal Hutan Lestari 6(3): 569-582

Proborini MW. 2012. Eksplorasi dan identifikasi jenis-jenis jamur kelas basidiomycetes di kawasan Bukit Jimbaran Bali. Jurnal Biologi 26 (2) : 45-47.

Putir EP, Mardji D. dan Simorangkir B.DAS. 2008. Keanekaragaman jenis jamur makroskopis pada dua jenis hutan berbeda di kalampangan zone cimtrop Kalimantan Tengah. Jurnal Kehutanan Tropika Humida 1(2).

Setiorini IJ. 2018. Keanekaragaman jenis jamur makroskopis dan karakter tempat tumbuhnya pada hutan rawa gambut sekunder di desa kuala dua kabupaten kubu raya Kalimantan Barat. Fakultas Kehutanan, Universitas Tanjungpura, Pontianak. Jurnal Hutan Lestari 6(1):158-164.

Swarnadwipa N, Hendra W. 2008. Pengertian jamur dengan dehumidifier. Jurnal Teknik Mesin Cakram 2(1):30-33

Tampubolon J. 2012. Inventarisasi Jamur Makroskopis Di Kawasan Ekowisata Bukit Lawing Kabupaten Langkat Sumatera Utara. Tesis Program Studi Magister Biologi FMIPA USU. Medan: USU Repository.

Wahyudi AE, Linda R., Khotimah S. 2012. Inventarisasi jamur makrokopis di hutan rawa gambut desa teluk bakung kecamatan sungai ambawang Kabupaten Kubu Raya. Jurnal Protobiont 1 (1): 8-11 